\title{
Synanthropic rodents as possible reservoirs of shigatoxigenic Escherichia coli strains
}

\section{Ximena Blanco Crivelli ${ }^{1}$, María V. Rumi ${ }^{2}$, Julio C. Carfagnini ${ }^{1}$, Osvaldo Degregorio ${ }^{3}$ and Adriana B. Bentancor ${ }^{2 *}$}

1 Facultad de Ciencias Veterinarias, Cátedra de Patología, Universidad de Buenos Aires, Buenos Aires, Argentina

${ }^{2}$ Facultad de Ciencias Veterinarias, Cátedra de Microbiología, Universidad de Buenos Aires, Buenos Aires, Argentina

${ }^{3}$ Facultad de Ciencias Veterinarias, Cátedra de Salud Pública, Universidad de Buenos Aires, Buenos Aires, Argentina

\section{Edited by:}

Nora Lía Padola, Universidad Nacional del Centro de la Provincia de Buenos Aires, Argentina

Reviewed by:

Enninga Jost, Pasteur Institute, France

Roberto M. Vidal, Universidad de Chile, Chile

*Correspondence:

Adriana B. Bentancor, Facultad de Ciencias Veterinarias, Cátedra de

Microbiología, Universidad de

Buenos Aires, Chorroarín 280,

Buenos Aires, (C1427 CWO),

Argentina.

e-mail:aben@fvet.uba.ar
Shigatoxigenic Escherichia coli (STEC) strains are worldwide zoonotic pathogen responsible for different cases of human disease including hemolytic uremic syndrome (HUS). Transmission of STEC to humans occurs through the consumption of food and water contaminated by faeces of carriers and by person-to-person contact. The objective of this study was two-fold: (1) to investigate whether synanthropic rodents are possible reservoirs of STEC in the urban area and (2) whether a particular genus out of synanthropic rodent is the principal carrier of STEC. One hundred and forty-five rodents were captured in Buenos Aires City. Screening for st $1 /$ stx 2 and rfbO 157 was done by PCR from the confluence zone. STEC isolates were further characterized with biochemical tests by standard methods. Additional virulence factors (eae, ehxA, and saa) were also determined by PCR. Forty-one of the rodents were necropsied and sample of kidney and small and large intestine were taken for histopathological diagnosis. The samples sections were stained with hematoxylin-eosin, and observed by light microscopy to evaluate the systemic involvement of these species in natural infections. STEC was isolated from seven out of 27 suspect animals at screening. The following genotypes were found in the STEC strains: st $\times 1 /$ st $x 2 / e h \times A(1)$, st $\times 2$ (4), st $x 2 / e h \times A(1), s t \times 2 / e h \times A / e a e(1)$. Neither gross nor microscopic lesions compatible with those produced by Shiga toxin were observed in the studied organs of necropsied rodents. The bivariate analysis including the 145 rodent's data showed that the isolation of STEC is associated positively to Rattus genus. This synanthropic species may play a role in the transmissibility of the agent thus being a risk to the susceptible population. Their control should be included specifically in actions to dismiss the contamination of food and water by STEC in the urban area, as additional strategies for epidemiological control.

Keywords: STEC, hemolytic uremic syndrome, Rattus, reservoir, synanthropic

\section{INTRODUCTION}

Shigatoxigenic Escherichia coli (STEC) strains are a worldwide zoonotic pathogen responsible for different cases of human disease including diarrhea, hemorrhagic colitis, and hemolytic uremic syndrome (HUS) (Karmali, 1989).

Unlike other commensal E. coli strains, STEC strains have several virulence genes which permit the evaluation of its pathogenic nature in the laboratory (stxl, stx2, eae, ehx $\mathrm{A}, \mathrm{saa}$ ) (Paton and Paton, 1998a, 2002). These strains may be screened by PCR of stx genes in cultured bacteriological samples and subsequent isolation of colonies stx ${ }^{+}$.

STEC was reported as inhabitant in the intestine of various animal species: cattle, sheep, pigs, goats (Beutin et al., 1993). There are few references of STEC in synanthropic animals (Hancock et al., 1998; Čižek et al., 1999; Nielsen et al., 2004).

The fecal-oral route is recognized as the major route of transmission, associated with raw or processed food, probably contaminated at some point of the production chain (Meichtri et al., 2004). Over years cattle has been involved as the principal reservoir of STEC, however, isolated strains are partially similar to those which have impact on public health (Boerlin et al., 1999; Rosser et al., 2008).

In the present work we investigated STEC in synanthropic rodents of Buenos Aires City, Argentina. The aim of this study was twofold: (1) to investigate whether synanthropic rodents are possible reservoirs of STEC in the urban area and (2) whether a particular genus of synanthropic rodent is a carrier of STEC.

\section{MATERIALS AND METHODS STUDY DESIGN}

A non-probabilistic sampling by convenience was carried out in Buenos Aires City. One hundred and forty-five rodents were captured using live traps (Sherman and cage traps). The traps were placed in parks at intervals of five meters, varying in number 
according to the surface and the characteristics of each site of capture. The traps remained active for four consecutive nights and they were checked daily in the morning.

The inclusion criteria for the sample from the rodent population of Buenos Aires City were "animals from parks which were captured alive." We studied the population groups that were validated by relevant epidemiological characteristics. The animals were classified according to genus and species. Each rodent was anesthetized to be weighed, measured, sexed, and their reproductive status was recorded. They were also sampled by two rectal swabs.

The study was approved by the Institutional Animal Care and Use of Experimental Animals, CICUAL, Faculty of Veterinary Science, University of Buenos Aires.

\section{DETECTION OF $s t \boldsymbol{x}^{+}$AND ISOLATION OF STEC STRAINS}

The samples were examined according to standard procedures for isolation of O157:H7 STEC and non-O157 STEC previously described (Bentancor et al., 2007). Briefly, for O157 STEC detection the samples were inoculated in $5 \mathrm{ml}$ of cefixime-tellurite (CT) tripteine soy broth (TBS) for enrichment and incubated $18 \mathrm{~h}$ at $37^{\circ} \mathrm{C}$. The cultures were streaked onto Sorbitol MacConkey Agar (CT-SMAC) and incubated overnight. Detection of nonO157 was performed inoculating the samples in $5 \mathrm{ml}$ of TSB and incubated overnight at $37^{\circ} \mathrm{C}$. The cultures were streaked onto MacConkey Agar (MAC) and incubated overnight.

Screening for stx $1 /$ st $x 2$ and $r f b \mathrm{O} 157$ from the confluence area (CT-SMAC and MAC) was done by Multiplex PCR (Leotta et al., 2005) using the primers of Pollard et al. (1990) and of Paton and Paton (1998b) (Table 1). To obtain the templates for PCR a sample from the confluence area was taken and suspended in $200 \mu \mathrm{l}$ of sterile distilled water. The suspension was boiled $10 \mathrm{~min}$ in a water bath and centrifuged at $1300 \mathrm{rpm}$ for $5 \mathrm{~min}$.
The supernatant was used as the DNA extract. The PCR mixture for each sample had a final volume of $50 \mu \mathrm{l}$, and contained $1.5 \mathrm{mM}$ of the two st $x 1$ specific primers, $0.3 \mathrm{mM}$ of the two st $x 2$ and $r f b \mathrm{O} 157$ specific primers, $200 \mathrm{mM}$ of each deoxyribonucleoside triphosphate and $1 \mathrm{U}$ of Go Taq (Promega) DNA polymerase in $1 \times$ buffer according to the manufacturer's instructions, and finally $6 \mu \mathrm{l}$ of the template from sample. PCR was performed in a Mastercycler Gradient Eppendorf under the following conditions: $5 \mathrm{~min}$ at $94^{\circ} \mathrm{C}$, followed by 30 cycles of: $45 \mathrm{~s}$ at $94^{\circ} \mathrm{C}, 30 \mathrm{~s}$ at $56^{\circ} \mathrm{C}, 30 \mathrm{~s}$ at $72^{\circ} \mathrm{C}$ and a final step of $7 \mathrm{~min}$ at $72^{\circ} \mathrm{C}$, maintaining it at $4^{\circ} \mathrm{C}$ until analysis. $10 \mu \mathrm{l}$ of each PCR product obtained were electrophoresed on $2 \%$ agarose gels and stained with ethidium bromide.

Positive samples at screening from the confluence zone were considered suspect. Each suspect sample was evaluated for the presence of $s t x^{+}$strains up to 50 CFU.

According to the results obtained by PCR, animals were classified into positive (positive screening with isolation of a $s t x^{+}$strain), suspect (positive screening without isolation) and negative (pathogen was not detected at screening).

\section{BIOCHEMICAL CHARACTERIZATION AND IDENTIFICATION OF VIRULENCE FACTORS}

STEC isolates were further characterized as $E$. coli after gram staining, oxidase, catalase, glucose oxidation-fermentation, indole, methyl red (MR), Voges Proskauer (VP), Simmons citrate, fermentation of sugars (lactose, sucrose, cellobiose, sorbitol, raffinose, dulcitol, rhamnose) $\mathrm{H}_{2} \mathrm{~S}$ production, yellow pigment, $\beta$-glucuronidase activity, lysine decarboxylase, ornithine decarboxylase, and mobility assessment (Mac Faddin, 2003). RapidID ONE System 20 test (Remel) was also done, and additional virulence factors ( $s a a, e a e, e h x \mathrm{~A}$ ) were determined by PCR (Paton and Paton, 1998a, 2002).

Table 1 | Primers used for PCR analysis.

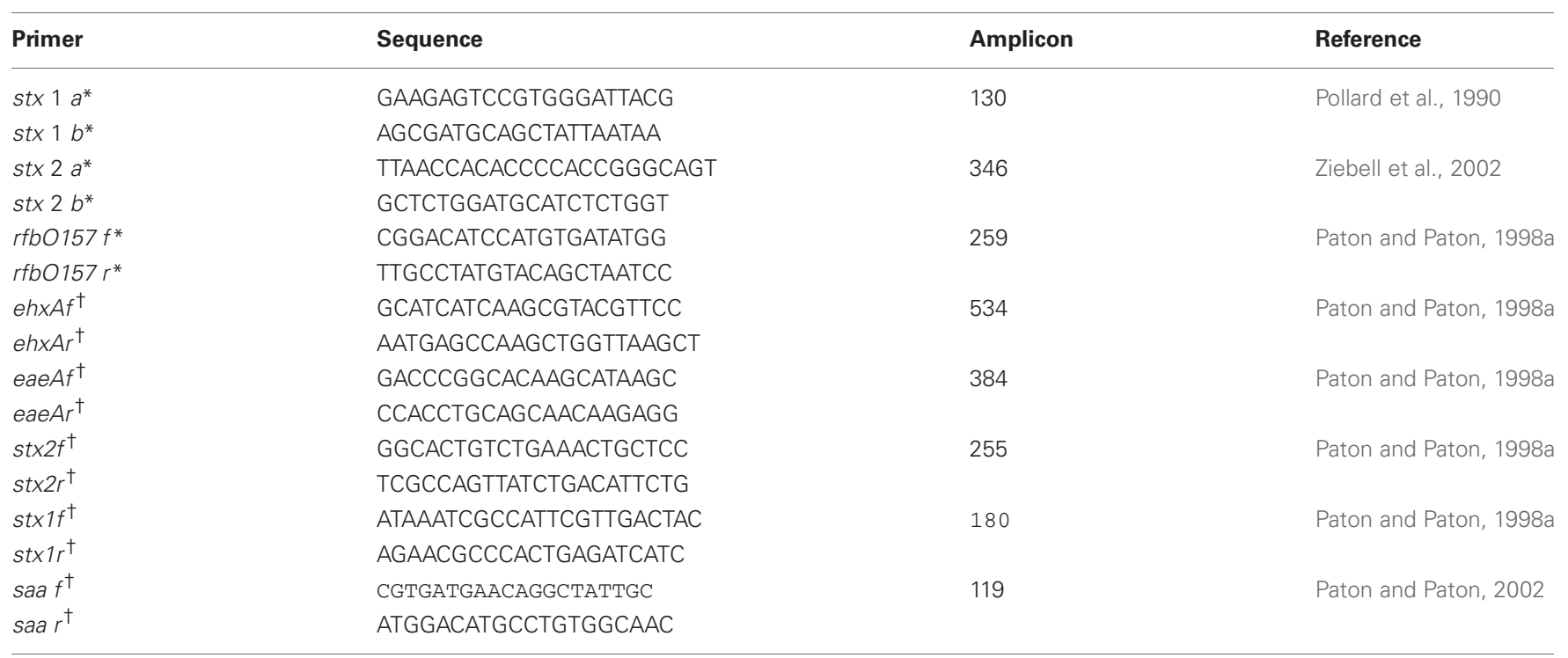

*Primers used at PCR screening.

${ }^{+}$Primers used in the study of virulence factors. 


\section{HISTOPATHOLOGY}

Necropsy of captured animals was performed to determine if STEC carriers had any injury. We looked for gross changes. Kidney, small, and large intestine were removed for histopathological diagnosis. The samples were fixed for $48 \mathrm{~h}$ in $10 \%$ buffered formalin and processed routinely. Sections of paraffinedembedded tissue were stained with hematoxylin-eosin and evaluated by light microscopy.

\section{STATISTICAL ANALYSIS}

The data obtained from each rodent were analyzed with EpiInfo 3.2 (CDC-WHO). We performed bivariate analysis (Chi-squared) and estimated OR and 95\% confidence interval for significant variables.

\section{RESULTS}

Rodents captured belonged to the following species: Deltamys kempi (n:4), Mus musculus (n:66), Oligoryzomys flavescens ( $n: 16)$, Rattus norvegicus ( $n: 31)$, Rattus rattus ( $n: 28)$.

PCR analysis was performed for all the rodents captured (145 animals). Twenty-seven out of 145 animals were suspected at PCR screening from the confluence area: Deltamys kempi (0/4); Mus musculus (10/66); Oligoryzomys flavescens (1/16); Rattus norvegicus (6/31); Rattus rattus (10/28) (Table 2).

Isolation of $s t x^{+}$strains was obtained in seven cases out of 27 suspect samples: Mus musculus (1/66), Rattus norvergicus (2/31), and Rattus rattus (4/28). Each isolated strain was identified as Escherichia coli by conventional bacteriological test and by RapidID ONE System 20 test. All the isolates were detected as non-O157 strains by PCR.

The following genotypes were found in the STEC strains: st $x 1 /$ st $x 2 / e h x \mathrm{~A}(1), \operatorname{st} x 2(4), \operatorname{st} x 2 / e h x \mathrm{~A}(1), \operatorname{st} x 2 / e h \times \mathrm{A} / e a e(1)$.

Forty-one out of 145 animals evaluated (five positive, four suspect and 32 negative) were necropsied. Neither gross nor microscopic lesions compatible with those produced by Shiga toxin were not observed in the studied organs.

The bivariate analysis including the 145 rodent data showed that the isolation of STEC is associated positively to Rattus genus ( $p: 0.01)$. The possibility of isolating STEC from rodents is higher in Rattus than in others genus (OR: 10,62, IC 95\%: 1,10-218,07).

\section{DISCUSSION}

Very little is known about the occurrence of STEC in synanthropic rodents. This study differs from others studies which captured rodents and searched for O157 STEC in sampling methods and procedures for isolation of strains (Hancock et al., 1998; Čižek et al., 1999), in our case the presence of O157 was not detected in these samples.

We isolated STEC strains in seven out to 27 suspect animals. This low number of isolates could be related to the number of CFU evaluated in positive animals at PCR screening from the confluence zone. We analyzed $50 \mathrm{CFU}$ from each suspect animal to avoid overestimated rodent species. It is possible that a low proportion of STEC in the suspect samples determinate a low recovery. On the other hand, sampling methods could be the cause of the low efficiency of isolation according to the low sample obtained.

Although rodents from different species were suspected at PCR screening, we observed a higher proportion in individuals of the Rattus genus. This fact is important because rodents from Rattus genus live in urban areas, overlaying their territory with men, feeding on waste and stowed food which can pollute. The growth of this population is related to their availability to food and water. When we discriminated these individuals by species, the study of carriage in $R$. norvegicus was lower than in $R$. rattus, opposed to the findings of different researchers who have not detected $R$. rattus as a carrier of STEC (Čižek et al., 1999; Nielsen et al., 2004). Differences between $R$. rattus and $R$. norvegicus could not be explained.

In Argentina the epidemiology of HUS included sporadic cases, opposite to large outbreaks of food borne diseases described in others countries. Synanthropic species as other sources deserve to be evaluated to mitigate the endemic presentation of the disease.

The capture of these animals was performed in the urban area, mainly in parks. Although the population of rats of Buenos Aires City is not determinate, larger sample with animals that come from other urban areas would be needed to establish whether there are differences between species in the urban cycle.

In the present study, one strain isolated genotype had st $x 1$ and all strains carried st $x 2$. The stx 2 is strongly associated with increased risk of HUS (Rivas et al., 2006). However, none of

Table 2 | Rodents evaluated as carrier of STEC and virulence profile of isolated strains.

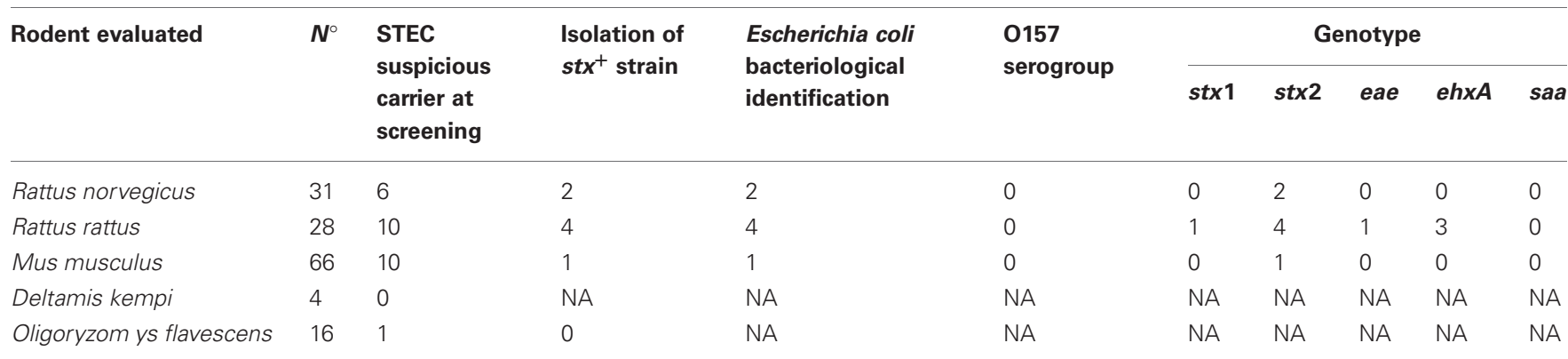

NA, not applicable. 
the isolated strains was from the $\mathrm{O} 157$ serogroup, which is most frequent as HUS producer.

The animals captured had no signs of disease; neither gross changes nor microscopic lesions compatible with those produced by Shiga toxin were observed in the studied organs. At the present time, lesions in rodents have been described in animal models which were inoculated orally or gastrointestinally with STEC, or by injection with Stx alone or with lipopolysaccharide component on the outer membrane of this bacterium (Obata, 2010). The absence of lesions may be due to Stx production, amount of Stx receptor (globotriaosylceramide, Gb3) in host cells and their sensitivity to Stx or complex biochemical aspects of the Gb3 membrane microenvironment (Obrig, 2010). Anyway, healthy synanthropic rodents could serve as a

\section{REFERENCES}

Bentancor, A., Rumi, M. V., Gentilini, M. V., Sardoy, C., Irino, K., Agostini, A., et al. (2007). Shiga toxin-producing and attaching and effacing $E$. coli in cats and dogs in a high hemolytic uremic syndrome incidence region in Argentina. FEMS Microbiol. Lett. 267, 251-256.

Beutin, L., Geier, D., Steinrück, H., Zimmemann, S., and Scheutz, F. (1993). Prevalence and some properties of verotoxin (Shiga-liketoxin) - producing Escherichia coli in seven different species of healthy domestic animals. J. Clin. Microbiol. 31, 2483-2488.

Boerlin, P., McEwen, S. A., BoerlinPetzold, F., Wilson, J. B., Johnson, R. P., and Gyles, C. L. (1999). Associations between virulence factors of shiga toxin-producing Escherichia coli and disease in humans. J. Clin. Microbiol. 37, 497-503.

Čižek, A., Alexa, P., Literák, I., Hamřik, J., Novák, P., and Smola, J. (1999). Shiga toxin-producing Escherichia coli $\mathrm{O} 157$ in feedlot cattle and Norwegian rats from a large-scale farm. Lett. Appl. Microbiol. 28, 435-439.

Hancock, D. D., Besser, T. E., Rice, E. D. E., Herriott, D. E., and Carpenter, L. V. (1998). Multiple sources of Escherichia coli $\mathrm{O} 157$ in feedlots and diary farms in the Northwestern, USA. Prev. Vet. Med. 35, 11-19.
Karmali, M. A. (1989). Infection by verocytotoxin-producing Escherichia coli. Clin. Microbiol. Rev. 2, 15-38.

Leotta, G. A., Chinen, I., Epszteyn, S., Miliwebsky, E., Melamed, I. C., Motter, M., et al. (2005). Validación de una técnica de PCR múltiple para la detección de Escherichia coli productor de toxina Shiga. Rev. Arg. Microbiol. 37, 1-10.

Mac Faddin, J. F. (2003). Pruebas Bioquímicas para la Identificación de Bacterias de Importancia Clínica. Buenos Aires: Ed. Médica Panamericana.

Meichtri, L., Miliwebsky, E., Gioffré, A., Chinen, I., Baschkier, A., Chillemi, G., et al. (2004). Shiga toxinproducing Escherichia coli in healthy young beef steers from Argentina: prevalence and virulence properties. Int. J. Food. Microbiol. 96, 189-198.

Nielsen, E. M., Skov, M. N., Madsen, and Baggesen, D. L. (2004). Verocytotoxin-producing Escherichia coli in wild birds and rodents in close proximity to farms. Appl. Environ. Microbiol. 70, 6944-6947.

Obata, F. (2010). Influence of Escherichia coli Shiga toxin on the mammalian central nervous system. Adv. Appl. Microbiol. 71, $1-20$.

Obrig, T. G. (2010). Escherichia coli Shiga Toxin mechanisms of action J. J., Lodal, J., Jespersen, J. B.,

reservoir of STEC as occurs in other animal species (Beutin et al., 1993). On the other hand the possibility that the animals consumed contaminated food and could be colonized transiently by STEC could not be excluded. It is difficult to estimate the time of excretion of STEC in wild animals that do not survive in captivity to determine if their carrier status is due to a transient colonization or whether we are in presence of a new reservoir of STEC. In order to obtain a finally conclusion about their role as reservoirs, larger sample would be need.

The results of the present study represent the first finding of STEC in $R$. rattus and show STEC no-O157 is circulating in different synanthropic rodent species of the urban area.

in renal disease. Toxins (Basel) 2, 2769-2794.

Paton, A. W., and Paton, J. C. (1998a). Detection and characterization of Shiga toxigenic E. coli by using multiplex PCR assays for stx 1, stx 2 , eaeA, enterohemorrhagic, E.coli hlyA, rfbO111, and rfbO157. J. Clin. Microbiol. 36, 598-602.

Paton, J. C., and Paton, A. W. (1998b). Pathogenesis and diagnosis of Shiga toxin-producing Escherichia coli infections. Clin. Microbiol. Rev. 11, 450-479.

Paton, A. W., and Paton, J. C. (2002). Direct detection and characterization of Shiga toxigenic Escherichia coli by multiplex PCR for stx 1, stx2, eae, ehxA, and saa. J. Clin. Microbiol. 40, 271-274.

Pollard, D. R., Johnson, W. M., Lior, H., Tyler, S. D., and Rozee, K. R. (1990). Rapid and specific detection of verotoxin genes in Escherichia coli by the polymerase chain reaction. J. Clin. Microbiol. 28, 540-545.

Rivas, M., Miliwebsky, E., Chinen, I., Deza, N., and Leotta, G. A. (2006). The epidemiology of hemolytic uremic syndrome in Argentina. Dignosis of the etiologic agent, reservoirs and routes of transmission. Medicina (B. Aires) 66(Suppl. 3), 27-32.

Rosser, T., Dransfield, T., Allison, L., Hanson, M., Holden, N., Evans, J., et al. (2008). Pathogenic potential of emergent sorbitol-fermenting
E. coli O157, NM. Infect. Immun. 76, 5598-5607.

Ziebell, K. A., Read, S. C., Johnson, R. P., and Gyles, C. L. (2002). Evaluation of PCR and PCRRFLP protocols for identifying Shiga toxins. Res. Microbiol. 153, 289-300.

Conflict of Interest Statement: The authors declare that the research was conducted in the absence of any commercial or financial relationships that could be construed as a potential conflict of interest.

Received: 28 May 2012; accepted: 14 October 2012; published online: 01 November 2012.

Citation: Blanco Crivelli X, Rumi MV, Carfagnini JC, Degregorio $O$ and Bentancor AB (2012) Synanthropic rodents as possible reservoirs of shigatoxigenic Escherichia coli strains. Front. Cell. Inf. Microbio. 2:134. doi: 10.3389/ fcimb.2012.00134

Copyright (C) 2012 Blanco Crivelli, Rumi, Carfagnini, Degregorio and Bentancor. This is an open-access article distributed under the terms of the Creative Commons Attribution License, which permits use, distribution and reproduction in other forums, provided the original authors and source are credited and subject to any copyright notices concerning any third-party graphics etc. 